\title{
Is a Minimum Wage an Appropriate Instrument for Redistribution?
}

\author{
By AART GERritsen and BAS JACOBS \\ Erasmus University Rotterdam
}

Final version received 2 August 2019.

\begin{abstract}
We analyse the redistributional (dis)advantages of a minimum wage over income taxation in competitive labour markets without imposing assumptions on the (in)efficiency of labour rationing. Compared to a distributionally equivalent tax change, a minimum-wage increase raises involuntary unemployment, but also raises skill formation as some individuals avoid unemployment. A minimum wage is an appropriate instrument for redistribution if and only if the public revenue gains from additional skill formation outweigh both the public revenue losses from additional unemployment and the utility losses of inefficient labour rationing. We show that this critically depends on how labour rationing is distributed among workers. A necessary condition for the desirability of a minimum-wage increase is that the public revenue gains from higher skill formation outweigh the revenue losses from higher unemployment. We write this condition in terms of measurable sufficient statistics.
\end{abstract}

\section{INTRODUCTION}

The minimum wage has recently been at the forefront of the public debate on income inequality. In 2013, US President Obama argued that income inequality is the defining challenge of our time and identified an increase in the minimum wage as a key step towards a more equal distribution of income (White House 2013). While a subsequent proposal to raise the federal minimum wage stranded in Congress, several US states, counties and cities responded by raising their city-wide minimum wages. At the same time, many European governments also turned to minimum-wage legislation in order to reduce income inequality. Widely publicized examples of this include the 2015 introduction of a federal minimum wage in Germany, and the 2016 implementation of a compulsory UK national 'living wage' for employees over 25 years of age. The obvious policy relevance of the minimum wage has spawned a large economic literature on the impact of minimum wages on levels of employment, the distribution of wages, and other labour market outcomes. ${ }^{1}$ However, there is relatively little economic theory on the desirability of a minimum wage vis-à-vis other instruments to redistribute income, such as progressive income taxation. As a result, no satisfactory answer has yet been given to the central question of this paper: is a minimum wage an appropriate instrument for redistribution?

Policy debates about minimum-wage reforms tend to be highly contentious. A striking illustration of this is a pair of rival letters sent to US federal policymakers in 2014. One of the letters favoured a higher minimum wage and the other opposed it, but both were signed by hundreds of economists, including several Nobel prize winners. ${ }^{2}$ One important reason for this controversy is that both proponents and opponents make arguments that are either subjective in nature or empirically contested. Proponents of the minimum wage emphasize the distributional benefits as it raises the earnings of lowskilled workers. However, the valuation of these distributional effects requires an intrinsically political judgment on which economists have little to say. Opponents of the minimum wage emphasize that it reduces employment. However, there is no agreement in the empirical literature on the adverse employment effects of the minimum wage (Card 
and Krueger 1995; Neumark and Wascher 2006; Schmitt 2013; Manning 2016). Thus it is hard to come to any consensus on the desirability of a minimum wage as long as the debate is framed in terms of the gains from more income redistribution versus the costs of higher unemployment. In this paper, we avoid this issue by analysing the minimum wage not in isolation from, but in comparison to redistribution via the tax and transfer system. This allows us to assess the desirability of a minimum wage with minimal reliance on political judgments about the value of redistribution or controversial estimates of the labour-demand effects of a minimum wage.

We develop a relatively standard model of occupational choice and optimal income redistribution, based on Diamond (1980) and Saez (2002), which we augment with a minimum-wage policy. Firms demand high-skilled and low-skilled labour in perfectly competitive labour markets. A minimum wage might be binding for low-skilled workers, but not for high-skilled workers. Individuals are assumed to be heterogeneous in their disutility of work in low-skilled and high-skilled occupations. This disutility represents both the effort costs of working in a given occupation and the costs of obtaining the necessary skills. Depending on their disutility of work, individuals decide to do highskilled work or low-skilled work, or to be (voluntarily) unemployed. A binding minimum wage fixes the low-skilled wage, thereby rationing some individuals out of the low-skilled labour market. Rationed individuals are unable to find a low-skilled job, and are therefore forced to choose between the high-skilled occupation and (involuntary) unemployment. We remain entirely agnostic about which individuals are, and which individuals are not, able to find a low-skilled job. Hence we adopt a fully general 'rationing schedule' that determines how rationing is distributed among individuals with different disutilities of work. This contrasts with most of the theoretical literature, which typically assumes that labour rationing is efficient, that is, that rationing is exclusively concentrated on individuals with the highest disutility of work. The general rationing schedule that we adopt — which includes efficient rationing as a special case-is more in line with the fact that we lack good empirical evidence on the distribution of labour rationing.

An important feature of our model is that the income redistribution of a minimumwage increase can be perfectly replicated by a change in income taxes. Perfectly competitive, profit-maximizing firms pay for the minimum wage by reducing high-skilled wages. As a result, the minimum wage redistributes income from individuals with a high income to individuals with a low income. The income tax could achieve the same income redistribution by reducing taxes on low-income earners and raising taxes on high-income earners. The relevant question therefore is: can a minimum wage achieve a given amount of income redistribution from high- to low-skilled workers at lower efficiency costs than the income tax? We obtain the answer to this question by analysing a policy reform that raises the minimum wage and simultaneously adjusts taxes to leave net incomes of both high- and low-skilled workers unaffected. We label this policy reform a net-incomeneutral (NIN) minimum-wage increase. The effects of an NIN minimum-wage increase precisely indicate how a minimum-wage increase differs from a distributionally equivalent change in taxes. ${ }^{3}$ As the policy reform leaves net incomes constant, it allows us to assess the desirability of a minimum-wage increase exclusively in terms of economic efficiency, without resorting to political judgments about the value of income redistribution. Our paper makes three contributions.

First, we show that a minimum-wage increase differs from a distributionally equivalent change in taxes by creating more unemployment and more high-skilled employment. Intuitively, an NIN increase in the minimum wage raises the wage costs of 
low-skilled workers. This reduces low-skilled labour demand and therefore rations some individuals out of the low-skilled labour market. While some of these rationed individuals become unemployed, others might prefer high-skilled employment over unemployment, and therefore choose to become high-skilled. The magnitude of the effects on unemployment and high-skilled employment is crucially determined by the rationing schedule. If rationing is mostly concentrated on individuals with a high (low) disutility of high-skilled work, then rationing mostly leads to higher unemployment (high-skilled employment). All other effects of a minimum-wage increase are identical to the effects of a distributionally equivalent tax change.

Second, we derive a simple condition under which the minimum wage is an appropriate instrument for redistribution. This is the case if a minimum-wage increase is more desirable than a distributionally equivalent change in taxes. The desirability condition reflects the three welfare-relevant effects of an NIN increase in the minimum wage. (i) Labour rationing reduces utility as long as the rationed individuals strictly prefer low-skilled work over unemployment or high-skilled work. (ii) Increased unemployment reduces public revenue if the unemployed pay fewer taxes than lowskilled workers. (iii) Increased high-skilled employment raises public revenue if highskilled workers pay more taxes than low-skilled workers. A minimum-wage increase is more desirable than a distributionally equivalent change in taxes if and only if the revenue gains from increased high-skilled employment are sufficiently high to compensate for the revenue losses of increased unemployment and the utility losses from inefficient rationing. If the desirability condition holds in the tax optimum without a minimum wage, then a minimum wage is necessarily part of the overall policy optimum. Both optimal and observed taxes tend to increase with income, and therefore distort labour participation and skill decisions downwards. The NIN minimum-wage increase exacerbates the distortion on labour participation by raising unemployment. However, it alleviates the tax distortion on skill formation by raising high-skilled employment. Hence the second-best role of the minimum wage is to alleviate tax distortions on skill formation.

Third, we derive a necessary condition for the desirability of a minimum-wage increase that is solely expressed in terms of three empirically recoverable statistics. Because an NIN minimum-wage increase leads to utility losses from inefficient rationing, the revenue gains from increased high-skilled employment must at least outweigh the revenue losses from increased unemployment for the minimum-wage increase to be desirable. This holds only if the increase in high-skilled employment is large enough relative to the increase in unemployment. That is, rationing should be sufficiently concentrated on individuals who prefer high-skilled employment over unemployment. The rationing schedule is therefore a crucial determinant of the desirability of a minimum wage. While we lack any empirical evidence on the rationing schedule, we show that the effect of unemployment on skill formation can function as a sufficient statistic, foregoing the need to determine the rationing schedule. Consequently, we can express the necessary condition for the desirability of a minimum-wage increase in terms of the tax wedge on participation, the tax wedge on skill formation, and the effect of unemployment on skill formation. This condition does not rely on controversial estimates of the labour-demand effects of a minimum wage. This is because both the benefits (more high-skilled employment) and the costs (more unemployment) of the NIN minimum-wage increase are proportional to the reduction in labour demand. ${ }^{4}$

The remainder of our paper is structured as follows. Section I discusses earlier literature. Section II introduces the theoretical model. Section III defines the NIN 
minimum-wage increase and derives its comparative statics. Section IV derives the welfare effects of an NIN minimum-wage increase and the conditions under which a minimum-wage increase is more desirable than a distributionally equivalent tax change. It also determines whether a binding minimum wage could be a desirable supplement to the tax optimum and considers the robustness of our results with respect to relaxing a number of theoretical assumptions. Section V concludes with some final thoughts.

\section{EARLIER LITERATURE}

This paper contributes to the literature that studies minimum wages in models of optimal income redistribution and competitive labour markets. Most studies consider the twotype optimal-tax framework of Stern (1982) and Stiglitz (1982). Using this framework, Allen (1987) and Guesnerie and Roberts (1987) find that a binding minimum wage is undesirable if the government could set non-linear income taxes. ${ }^{5}$ While they consider only underemployment on the labour-hours margin, Marceau and Boadway (1994) extend these analyses by considering involuntary unemployment on the extensive margin. They find that a minimum wage can be a desirable policy only if the unemployed receive smaller transfers than the low-skilled employed. In that case, labour participation is distorted upwards and a minimum wage alleviates this distortion by pushing some lowskilled individuals out of the labour market. We contribute to these studies by endogenizing the skill decisions of individuals. As a result, a minimum wage may yield not only an increase in unemployment, but also an increase in high-skilled employment. If skill formation is distorted downwards, then the minimum wage helps to alleviate the distortions on skill formation. These distortions are absent in previous studies because they assume that the skill distribution is exogenous.

The work of Lee and Saez (2012) is most closely related to our study. Like us, they introduce a minimum wage to the occupational-choice model of Diamond (1980) and Saez (2002). They assume that labour rationing is efficient so that only individuals with the lowest utility surplus of low-skilled work lose their jobs. A binding minimum wage allows the government to give a tax cut to the low-skilled without distorting the occupational choice of individuals. Intuitively, efficient rationing ensures that there are no low-skilled jobs for individuals who would want to get a low-skilled job in response to the tax cut. In their Proposition 2, Lee and Saez (2012) find that a minimum wage is desirable if low-skilled workers have a marginal social welfare weight that is larger than the average, which equals 1 in the optimum. Their Proposition 3 replicates Marceau and Boadway (1994). Both results can be seen as special cases of our more general desirability condition. We make four contributions compared to Lee and Saez (2012). First, we demonstrate that the second-best role of the minimum wage is to alleviate distortions on skill formation, which is not recognized by Lee and Saez (2012). Second, our desirability condition is valid for any efficient or inefficient rationing schedule and therefore does not require efficient rationing. Third, our desirability condition for a minimum-wage increase is valid at any initial allocation, not just at the tax optimum. ${ }^{6}$ Fourth, our desirability condition is written in terms of empirically measurable wedges and elasticities instead of subjective social welfare weights.

Also related are the works of Cahuc and Michel (1996) and Acemoglu (2001), who show that a minimum wage might be desirable because it shifts labour demand from lowto high-skilled jobs. While their results are therefore similar in spirit to ours, they both rely on considerably different welfare analyses. In Cahuc and Michel (1996), high-skilled employment is inefficiently low because of positive technological spillovers. In Acemoglu 
(2001), firms need to employ more capital to hire high-skilled workers than to hire lowskilled workers. The sunk-cost nature of these capital investments generates a hold-up problem that yields inefficiently low high-skilled employment. In contrast to these studies, in our framework high-skilled employment is inefficiently low because of a fiscal externality: due to the government's preference to redistribute income, high-skilled workers tend to pay more taxes than low-skilled workers.

A number of other studies shows that a minimum wage could be desirable alongside taxes and transfers if combined with other specific policies, or if low-skilled workers are heterogeneous in multiple dimensions. Boadway and Cuff (2001) consider the framework of Mirrlees (1971) and find that a minimum wage is desirable if it can be combined with a policy that forces the unemployed to accept any job that they can find. Danziger and Danziger (2015) find a useful role for the minimum wage if it can be combined with a policy that forces firms to hire a certain number of low-skilled workers, even if their marginal productivity is below the minimum wage. Blumkin and Danziger (2018) consider a case in which the government redistributes from 'lazy' to 'hard-working' lowskilled workers who earn the same wage rate, but vary in the number of hours that they work. They find that a minimum wage may function as a useful screening device if it reduces the labour hours of the lazy poor.

Finally, ever since Card and Krueger (1995), a large number of empirical studies find that the unemployment effects of a minimum wage are either small (e.g. Harasztosi and Lindner 2019) or statistically insignificant (e.g. Cengiz et al. 2019). This has led many to question the relevance of the framework of perfectly competitive labour markets (e.g. Schmitt 2013; Manning 2016). A small literature analyses the welfare properties of a minimum wage in non-competitive labour markets. Notable studies include Hungerbühler and Lehmann (2009), Cahuc and Laroque (2013), and Lavecchia (2019), which all consider a minimum wage along with optimal taxes. Cahuc and Laroque (2013) show that a minimum wage is not useful to reduce monopsony problems on the labour market as long as the government has sufficient tax instruments at its disposal. Hungerbühler and Lehmann (2009) and Lavecchia (2019) do find a role for a minimum wage alongside optimal non-linear labour income taxes if bargaining power of workers is inefficiently low and the government cannot directly control bargaining power. Even if our results were to indicate that a minimum wage is not an appropriate instrument for redistribution, it may still be a useful tool to alleviate market imperfections.

\section{MODEL}

This section describes labour-supply decisions of individuals, labour-demand decisions of firms, and the objective of the government. We develop a variation of the occupationalchoice models of Diamond (1980) and Saez (2002), extended with a binding minimum wage.

\section{Individuals}

We consider a continuum of individuals of mass 1 . The baseline model assumes that individuals differ in their ability $\theta$ and their occupation $i \in\{H, L, U\}$, which denotes whether individuals are high-skilled $(H)$, low-skilled $(L)$ or unemployed $(U)$. Ability is continuously distributed on support $[0, \bar{\theta}]$ according to a cumulative distribution function $G(\theta)$ with a corresponding density function $g(\theta)$. Based on their ability $\theta$, individuals decide to participate as a high-skilled worker and earn wage income $w^{H}$, to participate as 
a low-skilled worker and earn wage income $w^{L}$, where $w^{H}>w^{L}$, or not to participate at all and earn no wage income $\left(w^{U} \equiv 0\right)$. The government can impose a minimum wage by fixing the low-skilled wage $w^{L}$. Moreover, it levies differentiated income taxes $\tau^{i}$ for all observed levels of wage income $w^{i}$. If taxes for the unemployed are negative, then they receive an unemployment benefit $-\tau^{U}$. We assume that participation costs $\theta$ are private information. Hence, the government cannot distinguish between the voluntary unemployed and the involuntary unemployed, so they both receive the same unemployment benefits. Individuals spend all their net income on consumption: $c^{i}=w^{i}-\tau^{i}$.

Utility from consumption is given by an increasing and strictly concave function of consumption $c^{i}$, which is identical for all individuals: $v\left(c^{i}\right), v^{\prime}(\cdot)>0, v^{\prime \prime}(\cdot)<0$. When a worker of ability $\theta$ becomes low-skilled, she suffers disutility of work $1 / \theta$. When she becomes high-skilled, her disutility equals $(1+\beta) / \theta$. The parameter $\beta>0$ is a constant disutility markup of being high-skilled, which represents the effort costs of becoming high-skilled. Disutility of work is decreasing in ability $\theta$, and more so for high-skilled work than for low-skilled work. As a result, individuals with higher ability have a comparative advantage in high-skilled work. Non-participants do not incur any disutility of work. In Online Appendix C, we generalize our model to allow for two-dimensional heterogeneity, where individuals incur disutility of low-skilled work $1 / \theta^{L}$ and disutility of high-skilled work $1 / \theta^{H}$, with $\theta^{L}$ and $\theta^{H}$ drawn from a joint distribution $G\left(\theta^{L}, \theta^{H}\right) .^{7}$ All our main results carry over to the more general setting. We return to this when discussing the robustness of our results.

Utilities of the high-skilled, the low-skilled, and the unemployed are thus given by

$$
\begin{aligned}
& V_{\theta}^{H} \equiv v\left(w^{H}-\tau^{H}\right)-\frac{1+\beta}{\theta}, \\
& V_{\theta}^{L} \equiv v\left(w^{L}-\tau^{L}\right)-\frac{1}{\theta}, \\
& V^{U} \equiv v\left(-\tau^{U}\right),
\end{aligned}
$$

where subscripts indicate that both high- and low-skilled utility depend on individual ability $\theta$. Each individual optimally decides whether to participate in the labour market and whether to work as a low-skilled or a high-skilled worker. Figure 1 provides a stylized graph of utility as a function of ability. $\Theta_{1} \equiv\left\{\theta: V^{U}=V_{\theta}^{L}\right\}$ is the ability level at which an individual is indifferent between unemployment and low-skilled employment. $\Theta_{2} \equiv\left\{\theta: V^{U}=V_{\theta}^{H}\right\}$ is the ability level at which an individual is indifferent between unemployment and high-skilled employment. $\Theta_{3} \equiv\left\{\theta: V_{\theta}^{L}=V_{\theta}^{H}\right\}$ is the ability level at which an individual is indifferent between low-skilled and high-skilled employment. Equations (1)-(3) imply that $\Theta_{1}, \Theta_{2}$ and $\Theta_{3}$ are uniquely determined and equal to

$$
\begin{aligned}
& \Theta_{1}=\frac{1}{v\left(w^{L}-\tau^{L}\right)-v\left(-\tau^{U}\right)}, \\
& \Theta_{2}=\frac{1+\beta}{v\left(w^{H}-\tau^{H}\right)-v\left(-\tau^{U}\right)}, \\
& \Theta_{3}=\frac{\beta}{v\left(w^{H}-\tau^{H}\right)-v\left(w^{L}-\tau^{L}\right)} .
\end{aligned}
$$


A higher unemployment benefit $\left(-\tau^{U}\right)$ makes non-participation more attractive and therefore raises $\Theta_{1}$ and $\Theta_{2}$. Similarly, an increase in low-skilled net income $\left(w^{L}-\tau^{L}\right)$ makes low-skilled employment more attractive and therefore lowers $\Theta_{1}$ and raises $\Theta_{3}$. Finally, an increase in high-skilled net income $\left(w^{H}-\tau^{H}\right)$ makes high-skilled employment more attractive and therefore lowers both $\Theta_{2}$ and $\Theta_{3}$. We focus on non-trivial equilibria that contain at least some high- and low-skilled workers, which requires that $\bar{\theta}>\Theta_{3}>\Theta_{2}>\Theta_{1}{ }^{8}$ In terms of Figure 1, this implies that high- and low-skilled utility curves cross somewhere above the line for unemployed utility.

Labour-supply decisions of individuals are determined by their preference orderings over the different occupations. Figure 1 clearly illustrates how these preferences depend on ability $\theta$. Individuals with low ability $\theta \in\left[0, \Theta_{1}\right)$ prefer non-participation over anything else. Individuals with high ability $\theta \in\left(\Theta_{3}, \bar{\theta}\right]$ prefer high-skilled employment over anything else. And individuals with intermediate ability $\theta \in\left[\Theta_{1}, \Theta_{3}\right]$ prefer lowskilled employment over anything else. However, with a binding minimum wage, not every individual with ability $\theta \in\left[\Theta_{1}, \Theta_{3}\right]$ is able to find a low-skilled job. This is because a minimum wage $w^{L}$ makes low-skilled employment more attractive, while-as we show below-reducing low-skilled labour demand. This results in low-skilled labour rationing.

In our baseline model, we assume that individuals know whether they are able to find a low-skilled job before making their labour-supply decisions. When individuals figure out that they cannot find a low-skilled job, they must decide between (involuntary) unemployment and high-skilled employment. As illustrated in Figure 1, rationed individuals with ability $\theta \in\left[\Theta_{1}, \Theta_{2}\right)$ prefer unemployment over high-skilled employment and thus become unemployed. Rationed individuals with ability $\theta \in\left[\Theta_{2}, \Theta_{3}\right]$ prefer high-skilled employment over unemployment and become high-skilled employed.

Alternatively, we could assume that individuals make their labour-supply decisions before knowing whether they are able to find a low-skilled job. Individual labour supply then depends on the expected utility of low-skilled work, which itself depends on the probability of finding a job. We show in Online Appendix B that our main results are not affected by this alternative sequencing of rationing and labour-supply decisions. We briefly return to this when discussing the robustness of our theoretical results.

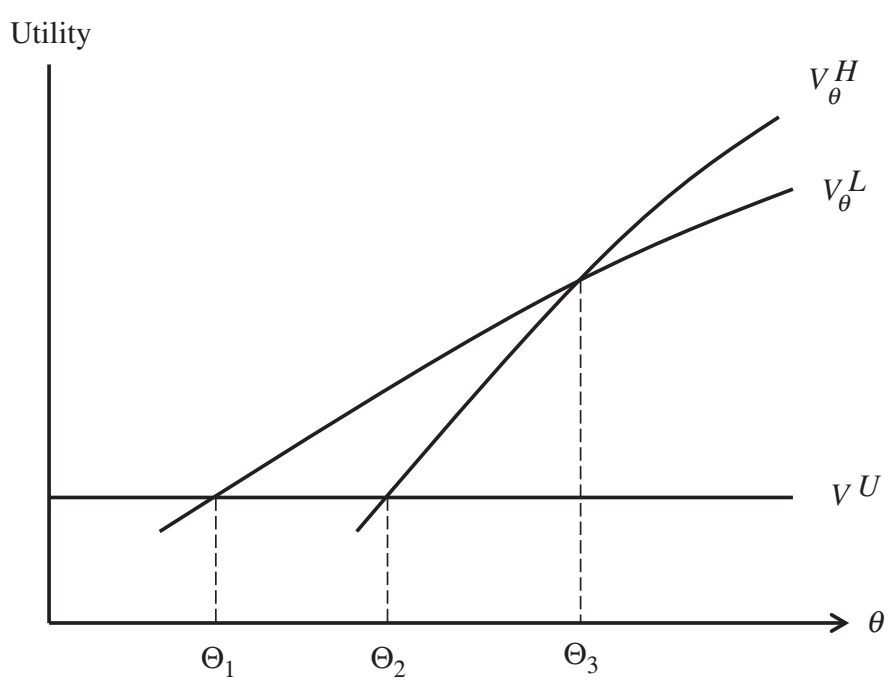

FIGURE 1. Utility as a function of ability. 


\section{Rationing and aggregate labour supply}

Aggregate supply of high- and low-skilled labour depends on which workers are not able to find a low-skilled job. The proportion of individuals with ability $\theta$ who are not able to find a job is denoted by the rationing rate $u_{\theta} \cdot{ }^{9}$ The rationing schedule is the set of all rationing rates.

Definition 1. The rationing schedule $\left\{u_{\theta}\right\}$ assigns a rationing rate $u_{\theta}$ to every ability level $\theta \in\left[\Theta_{1}, \Theta_{3}\right]$, which specifies the proportion of individuals with ability $\theta$ who are not able to find a low-skilled job.

By imposing no structure on the rationing schedule, we remain agnostic about which workers are unable to find a low-skilled job due to a binding minimum wage. We later demonstrate that the rationing schedule critically affects the desirability of a minimum wage.

Earlier literature on minimum wages most often assumes that rationing is efficient. Thus if low-skilled workers are heterogeneous, then earlier studies usually assume that rationing affects only individuals who have the lowest utility surplus of work (e.g. Boadway and Cuff 2001; Lee and Saez 2012; Blumkin and Danziger 2018). If low-skilled workers are homogeneous, then earlier studies assume either that rationing takes place on the intensive margin (Allen 1987; Guesnerie and Roberts 1987), or that low-skilled workers are indifferent between working and not working (Marceau and Boadway 1994). In both cases, the utility losses of rationing are second-order. Uniform or random rationing is sometimes considered as an alternative to efficient rationing. In that case, the likelihood that someone is rationed out of the low-skilled labour market is the same for everyone (e.g. Lee and Saez 2008; Gerritsen and Jacobs 2013).

It is theoretically and empirically unclear why labour rationing would be either efficient or uniform (Luttmer 2007). There is generally no secondary market for jobs that could (re)allocate jobs to individuals with the highest utility surplus of work. This makes it unlikely that rationing is efficient. At the same time, there is also little reason to expect that rationing is uniform and therefore entirely independent of individuals' surplus of work. Thus an important contribution of our study is that we consider minimum wages without imposing any specific rationing schedule. Our general rationing schedule could capture any arbitrary relationship between rationing and ability, and contains efficient and uniform rationing as special cases. ${ }^{10}$

Aggregating the labour supply of all individuals, while using the definition of the rationing schedule, yields the following expressions for aggregate high- and low-skilled labour supply, and unemployment:

$$
\begin{aligned}
& H=1-G\left(\Theta_{3}\right)+\int_{\Theta_{2}}^{\Theta_{3}} u_{\theta} \mathrm{d} G(\theta), \\
& L=\int_{\Theta_{1}}^{\Theta_{3}}\left(1-u_{\theta}\right) \mathrm{d} G(\theta), \\
& U=G\left(\Theta_{1}\right)+\int_{\Theta_{1}}^{\Theta_{2}} u_{\theta} \mathrm{d} G(\theta) .
\end{aligned}
$$

Figure 2 provides a graphical illustration of aggregate labour supply. For illustrative purposes, we show the case of a uniform ability distribution, so that $g(\theta)$ is constant. The 


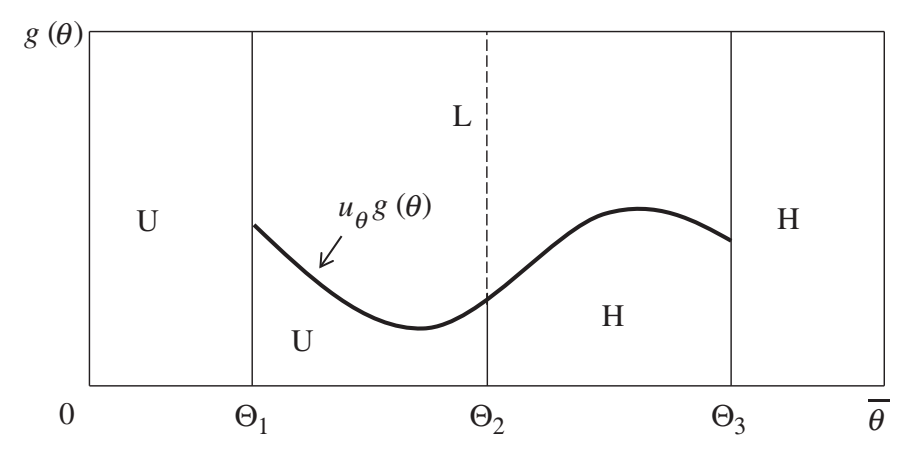

FIGURE 2. A stylized representation of equilibrium.

area below the rationing curve $u_{\theta} g(\theta)$ represents the individuals who are rationed out of the low-skilled labour market. Depending on their ability, they become either unemployed or high-skilled employed. The area above the rationing curve represents the individuals who are not rationed out of the low-skilled labour market. Thus the areas denoted by $U$ represent voluntary and involuntary unemployment. The area denoted by $L$ represents low-skilled employment. And the areas denoted by $H$ represent high-skilled employment.

\section{Firms}

Aggregate demand for high-skilled workers is denoted by $H^{d}$, and aggregate demand for low-skilled workers is denoted by $L^{d}$. A competitive, representative firm takes wages as given and demands high- and low-skilled labour to maximize profits. Workers of the same skill type-but different ability $\theta$ - are perfect substitutes in production, whereas high-skilled labour and low-skilled labour are imperfect substitutes in production. The production technology $F(\cdot)$ is homogeneous of degree 1, and given by

$$
F\left(H^{d}, L^{d}\right), \quad F_{H}, F_{L}>0, \quad F_{H H}, F_{L L}<0, \quad F_{H L}>0,
$$

where subscripts denote partial derivatives. Production features positive but diminishing marginal products of both factors. High- and low-skilled labour are cooperant factors of production. Profit-maximization requires that marginal labour products equal wages: ${ }^{11}$

$$
\begin{aligned}
& F_{H}\left(H^{d}, L^{d}\right)=w^{H}, \\
& F_{L}\left(H^{d}, L^{d}\right)=w^{L} .
\end{aligned}
$$

Due to constant returns to scale in production, there are no pure profits in equilibrium. Equations (11) and (12) imply downward-sloping labour demand curves. As a result, a higher minimum wage is associated with reduced low-skilled labour demand.

\section{Equilibrium}

For a given government policy $\left\{w^{L}, \tau^{U}, \tau^{L}, \tau^{H}\right\}$, equations (7)-(9) describe aggregate high- and low-skilled labour supplies as functions of the high-skilled wage and the 
rationing schedule. Equations (11) and (12) describe aggregate labour demand as a function of the high-skilled wage. The economy is in general equilibrium if the highskilled wage and the rationing schedule are such that aggregate labour supply equals labour demand: $H=H^{d}$ and $L=L^{d}$. Because the minimum wage is binding only for low-skilled labour, the high-skilled wage freely adjusts to ensure that the high-skilled labour market clears in equilibrium. However, a binding minimum wage makes lowskilled wage adjustments impossible. Instead, labour rationing adjusts to ensure equilibrium on the low-skilled labour market. As can be seen from Figure 2, there are an infinite number of possible rationing schedules $\left\{u_{\theta}\right\}$ that yield the same equilibrium levels of aggregate employment. This indeterminacy has important implications for the comparative statics and welfare effects of the minimum wage, as we show in the following sections.

\section{Government}

The government sets a minimum wage $w^{L}$ and income taxes $\left\{\tau^{H}, \tau^{L}, \tau^{U}\right\}$. The critical informational assumption of our analysis is that individual earnings are verifiable. The government can thus simultaneously implement an income tax and enforce a binding minimum wage for the low-skilled. Our approach is informationally consistent because the implementations of both the income tax and the minimum wage require the same information on individual earnings. ${ }^{12}$

We assume that the social welfare function $\mathcal{W}$ is utilitarian:

$$
\mathcal{W} \equiv U V^{U}+\int_{\Theta_{1}}^{\Theta_{2}}\left(1-u_{\theta}\right) V_{\theta}^{L} \mathrm{~d} G(\theta)+\int_{\Theta_{2}}^{\Theta_{3}} u_{\theta} V_{\theta}^{H} \mathrm{~d} G(\theta)+\int_{\Theta_{3}}^{\bar{\theta}} V_{\theta}^{H} \mathrm{~d} G(\theta) .
$$

None of our findings depend on the assumption of a utilitarian social welfare function. Stronger redistributional concerns can be introduced by, for example, weighting individual utilities with Pareto weights or by summing over a concave transformation of individual utilities. The government budget constraint $\mathcal{B}$ is given by

$$
\mathcal{B} \equiv U \tau^{U}+L \tau^{L}+H \tau^{H}-R=0,
$$

where $R$ is an exogenous revenue requirement.

\section{A Net-Income-Neutral Minimum-WAge InCREASE}

Defining the net-income-neutral minimum-wage increase

A minimum wage can raise the income of low-skilled workers, but so can the tax system. ${ }^{13}$ The relevant question therefore is: how does a change in the minimum wage differ from a distributionally equivalent change in the income tax system? This question can be approached in two different but equivalent ways. One could derive the effects of an increase in the minimum wage in isolation, as well as the effects of a distributionally equivalent tax change, and then take the difference between the effects of the two separate reforms. Or one could derive the effects of a combined reform that simultaneously raises the minimum wage and adjusts taxes to leave net wages unaffected. Both approaches are logically equivalent and therefore yield identical results. We take the latter approach and label the combined reform a net-income-neutral (NIN) increase in the minimum wage. 
Analysing an NIN increase in the minimum wage has several important advantages. First, the NIN minimum-wage increase allows us to ignore many behavioural effects that a minimum-wage increase has in common with a distributionally equivalent change in taxes. This greatly reduces the analytical complexity associated with deriving the comparative statics. ${ }^{14}$ Second, because the reform leaves net incomes unaffected, we can focus the welfare analysis exclusively on the efficiency gains and losses of a minimum-wage increase relative to a distributionally equivalent change in taxes. This allows us to analyse the desirability of a minimum wage without taking a stance on inherently subjective political preferences for income redistribution. ${ }^{15,16}$ Third, the welfare analysis of the reform gives a necessary condition for the relative desirability of a minimum wage that is expressed solely in terms of sufficient statistics that could be measured empirically.

The following lemma formally defines the NIN minimum-wage increase and derives the changes in taxes that are necessary to maintain net-income neutrality.

Lemma 1. A net-income-neutral increase in the minimum wage raises the minimum wage by $\mathrm{d} w^{L}>0$, keeps the unemployment benefit constant $\left(\mathrm{d} \tau^{U}=0\right)$, raises the low-skilled tax by $\mathrm{d} \tau^{L}=\mathrm{d} w^{L}$, and lowers the high-skilled tax such that $\mathrm{d} \tau^{H}=\mathrm{d} w^{H}=$ $-(L / H) \mathrm{d} w^{L}<0$.

Proof. Equate the total derivative of net income $w^{i}-\tau^{i}$ to zero to find $\mathrm{d} \tau^{i}=\mathrm{d} w^{i}$ for $i \in\{H, L, U\}$. Linear homogeneity of the production function together with equations (11) and (12) implies zero equilibrium profits: $F(H, L)-w^{H} H-w^{L} L=0$. Take the total derivative and rearrange to find $H \mathrm{~d} w^{H}=-L \mathrm{~d} w^{L}$. Rewrite to obtain the result.

A minimum wage compresses the wage differential between high- and low-skilled workers due to complementarity of labour types in production (i.e. $F_{H L}>0$ ). Intuitively, an increase in the low-skilled wage drives down low-skilled labour demand, which, in turn, lowers the productivity and wages of high-skilled workers. The increase in the low-skilled wage is fully paid for by a decrease in high-skilled wages $\left(H \mathrm{~d} w^{H}=-L \mathrm{~d} w^{L}\right)$. This follows logically from the absence of profits due to constant returns to scale in production. To fully neutralize the changes in gross wages, the NIN minimum-wage reform therefore raises low-skilled taxes and lowers high-skilled taxes, while keeping unemployment benefits constant.

\section{Comparative statics}

The behavioural effects of the NIN minimum-wage increase are critical for the welfare analysis that we conduct below. We graphically illustrate the effects of the NIN minimum-wage increase in Figure 3. The policy reform has no effect on individual preferences for different occupations. Since net wages do not change, equations (4)-(6) imply that the cut-offs $\Theta_{1}, \Theta_{2}$ and $\Theta_{3}$ remain unaffected. The only effect of the policy reform is that individuals may change their occupation due to a change in low-skilled labour rationing. The NIN minimum-wage increase raises low-skilled labour costs, and therefore results in a reduction of low-skilled employment $(\mathrm{d} L<0)$. This is indicated by the upward shift of the rationing schedule in Figure 3. As a result, some individuals with ability $\theta \in\left[\Theta_{1}, \Theta_{2}\right)$ might lose their low-skilled jobs and move into unemployment $(\mathrm{d} U \geq 0)$. These rationed workers prefer unemployment over high-skilled employment. Similarly, some individuals with ability $\theta \in\left[\Theta_{2}, \Theta_{3}\right]$ might also lose their low-skilled 


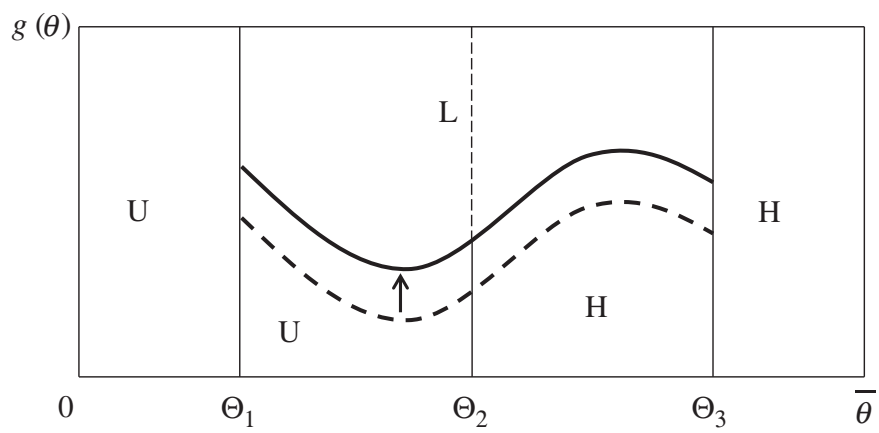

FIGURE 3. Comparative statics of a net-income-neutral minimum-wage increase.

jobs, and move into high-skilled employment $(\mathrm{d} H \geq 0)$. These workers prefer high-skilled employment over unemployment.

What happens to unemployment and high-skilled employment crucially depends on how the increase in rationing is distributed among low-skilled workers; that is, it depends on the change in the rationing schedule. In what follows, we use $\rho$ as a measure of the proportion of additional rationing that is concentrated on individuals who prefer highskilled employment over unemployment:

$$
\rho \equiv \frac{\int_{\Theta_{2}}^{\Theta_{3}} \mathrm{~d} u_{\theta} \mathrm{d} G(\theta)}{\int_{\Theta_{1}}^{\Theta_{3}} \mathrm{~d} u_{\theta} \mathrm{d} G(\theta)}=\frac{\mathrm{d} H}{-\mathrm{d} L} \in[0,1] .
$$

In terms of Figure 3, $\rho$ measures the increase in the areas denoted by $H$ relative to the decrease in the area denoted by $L$. The larger $\rho$, the more a given increase in labour rationing translates into an increase in high-skilled employment. We assume that $\mathrm{d} u_{\theta} \geq 0$ for all $\theta$, which ensures that $\rho \in[0,1]$. At one extreme, if $\rho=1$, then all additional rationing is concentrated on low-skilled workers with relatively high ability. In that case, rationing leads to more high-skilled employment without causing any increase in unemployment. At the other extreme, if $\rho=0$, then all additional rationing is concentrated on low-skilled workers with relatively low ability. In that case, rationing does not affect high-skilled employment but only raises unemployment. Armed with the definition of $\rho$, we can formally state the comparative statics of an NIN minimum-wage increase in the following Lemma.

Lemma 2. The general-equilibrium comparative statics of the NIN minimum-wage increase, as described by Lemma 1, are

$$
\begin{aligned}
& \mathrm{d} V^{U}=\mathrm{d} V_{\theta}^{L}=\mathrm{d} V_{\theta}^{H}=\mathrm{d} \Theta_{1}=\mathrm{d} \Theta_{2}=\mathrm{d} \Theta_{3}=0, \\
& \mathrm{~d} H=\int_{\Theta_{2}}^{\Theta_{3}} \mathrm{~d} u_{\theta} \mathrm{d} G(\theta)=\rho \alpha \varepsilon \frac{\mathrm{d} w^{L}}{w^{L}} \geq 0, \\
& \mathrm{~d} L=\int_{\Theta_{1}}^{\Theta_{3}} \mathrm{~d} u_{\theta} \mathrm{d} G(\theta)=-\alpha \varepsilon \frac{\mathrm{d} w^{L}}{w^{L}}<0,
\end{aligned}
$$




$$
\mathrm{d} U=\int_{\Theta_{1}}^{\Theta_{2}} \mathrm{~d} u_{\theta} \mathrm{d} G(\theta)=(1-\rho) \alpha \varepsilon \frac{\mathrm{d} w^{L}}{w^{L}} \geq 0,
$$

where $\varepsilon \equiv-F_{L} /\left(L F_{L L}\right)>0$ is the labour-demand elasticity and $\alpha \equiv(1 / L+\rho / H)^{-1}>0$ is a share parameter.

Proof. See the Appendix.

As the reform is net-income neutral, it leaves occupation-specific utility unaffected. This is shown in equation (16). However, some individuals may still incur a utility loss, because an increase in rationing forces them out of a low-skilled job and into a lesspreferred occupation. Relative to a distributionally equivalent change in taxes, a minimum-wage increase leads to a reduction in low-skilled employment $(\mathrm{d} L<0)$. This (weakly) increases both unemployment $(\mathrm{d} U \geq 0)$ and high-skilled employment $(\mathrm{d} H \geq 0)$. The reduction in low-skilled employment is equal to the total increase in rationing due to an NIN minimum-wage increase, as shown by equation (18). Unsurprisingly, the higher the labour-demand elasticity $\varepsilon$, the larger the increase in low-skilled labour rationing. A fraction $\rho$ of the additional labour rationing reflects an increase in high-skilled employment; that is, $\mathrm{d} H=-\rho \mathrm{d} L \geq 0$, as shown in equation (17). As long as $\rho>0$, the NIN reform leads to more high-skilled employment. Similarly, a fraction $1-\rho$ of the additional rationing reflects higher unemployment; that is, $\mathrm{d} U=-(1-\rho) \mathrm{d} L \geq 0$, as shown in equation (19). As long as $\rho<1$, the NIN reform leads to more unemployment.

The idea that rationing raises high-skilled employment plays a crucial role in the welfare analysis of the minimum wage. It is therefore important to emphasize that this effect of rationing is not merely a theoretical possibility. There is a sizeable literature that confirms the empirical relevance of a positive relationship between low-skilled unemployment and skill formation; see, for instance, Clark (2011) for the UK, Kane (1994) and Card and Lemieux (2001) for the USA, and Petrongolo and San Segundo (2002) for Spain. While these studies tend to focus on the effects of business-cycle fluctuations in unemployment, recent evidence indicates that more structural declines in employment opportunities have had a similar effect on skill formation. Foged and Peri (2015) study the effects of a plausibly exogenous increase in immigration, and show that low-skilled immigrants push low-skilled native workers towards more non-manual and better-paid occupations. In line with our theoretical prediction, this suggests that a decline in employment opportunities for low-skilled workers leads them to improve their skills. $^{17}$

\section{WELFARE ANALYSIS}

\section{A desirability condition for the minimum wage}

The following proposition is the main result of the paper. It provides the condition under which a minimum-wage increase is more desirable than a distributionally equivalent change in the tax system.

Proposition 1. A minimum-wage increase is more desirable than a distributionally equivalent change in the tax system if and only if an NIN minimum-wage increase raises social welfare, so that the following condition is satisfied: 


$$
\rho\left(\tau^{H}-\tau^{L}\right)-(1-\rho)\left(\tau^{L}-\tau^{U}\right)>(1-\rho)\left(\frac{\bar{V}_{12}^{L}-V^{U}}{\lambda}\right)+\rho\left(\frac{\bar{V}_{23}^{L}-\bar{V}_{23}^{H}}{\lambda}\right),
$$

where $\lambda$ is the shadow value of public resources,

$$
\bar{V}_{12}^{L} \equiv \frac{\int_{\Theta_{1}}^{\Theta_{2}} V_{\theta}^{L} \mathrm{~d} u_{\theta} \mathrm{d} G(\theta)}{\int_{\Theta_{1}}^{\Theta_{2}} \mathrm{~d} u_{\theta} \mathrm{d} G(\theta)} \quad \text { and } \quad \bar{V}_{23}^{L} \equiv \frac{\int_{\Theta_{2}}^{\Theta_{3}} V_{\theta}^{L} \mathrm{~d} u_{\theta} \mathrm{d} G(\theta)}{\int_{\Theta_{2}}^{\Theta_{3}} \mathrm{~d} u_{\theta} \mathrm{d} G(\theta)}
$$

are the average low-skilled utilities of the individuals who are rationed by the reform and have ability $\theta \in\left[\Theta_{1}, \Theta_{2}\right)$ and $\theta \in\left[\Theta_{2}, \Theta_{3}\right]$, respectively, and

$$
\bar{V}_{23}^{H} \equiv \frac{\int_{\Theta_{2}}^{\Theta_{3}} V_{\theta}^{H} \mathrm{~d} u_{\theta} \mathrm{d} G(\theta)}{\int_{\Theta_{2}}^{\Theta_{3}} \mathrm{~d} u_{\theta} \mathrm{d} G(\theta)}
$$

is the average high-skilled utility of the individuals who are rationed by the reform and have ability $\theta \in\left[\Theta_{2}, \Theta_{3}\right]$.

\section{Proof. See the Appendix.}

In the previous section, Lemma 2 established that an NIN increase in the minimum wage raises unemployment and high-skilled employment at the cost of reduced low-skilled employment, while leaving utility within any occupation unaffected. In line with this, Proposition 1 establishes that the NIN minimum-wage reform affects social welfare only through changes in utility and public revenue that are caused by the increases in highskilled employment and unemployment. The left-hand side of equation (20) captures the welfare effects of the potential public revenue gains $(\mathrm{d} \mathcal{B})$, whereas the right-hand side represents the welfare effects of the potential utility losses $(-\mathrm{d} \mathcal{W} / \lambda)$. We can distinguish four welfare-relevant effects of the NIN increase in the minimum wage: (i) it raises public revenue from individuals who become high-skilled if $\tau^{H}>\tau^{L}$ (first left-hand-side term); (ii) it reduces public revenue from individuals who become unemployed if $\tau^{L}>\tau^{U}$ (second left-hand-side term); (iii) it lowers the utility of individuals who become involuntarily unemployed (first right-hand-side term); and (iv) it lowers the utility of individuals who become involuntarily high-skilled employed (second right-hand-side term).

An NIN increase in the minimum wage leads to utility losses because rationed individuals strictly prefer low-skilled work over any alternative occupation. This is shown by the right-hand side of equation (20). Some rationed individuals become unemployed and suffer utility losses that are - expressed in monetary units—on average equal to $\left(\bar{V}_{12}^{L}-V^{U}\right) / \lambda$. This term is scaled by the proportion of rationed individuals who become unemployed $(1-\rho)$. Other rationed individuals switch to high-skilled employment and suffer utility losses that are — expressed in monetary units — on average equal to $\left(\bar{V}_{23}^{L}-\bar{V}_{23}^{H}\right) / \lambda$. This term is scaled by the proportion of rationed individuals who become high-skilled $(\rho)$. The total utility loss of the NIN minimum-wage increase crucially depends on the efficiency of the rationing schedule. In the case of efficient rationing, all rationing is concentrated on individuals who are indifferent between low- 
skilled employment and high-skilled employment or unemployment (i.e. on those who have ability $\Theta_{1}$ or $\Theta_{3}$ ). In that case, $\bar{V}_{12}^{L}=V^{U}$ and $\bar{V}_{23}^{L}=\bar{V}_{23}^{H}$, so that $\mathrm{d} \mathcal{W}=0$ and the right-hand side of equation (20) vanishes. In any other case, the more inefficient rationing - that is, the more rationing is concentrated around ability $\Theta_{2}$ - the higher the utility losses associated with the minimum wage, and therefore the larger the right-hand side of equation (20).

Thus the (in)efficiency of the rationing schedule determines the degree to which a minimum wage generates utility losses. This has been pointed out by a number of earlier studies (e.g. Lott 1990; Marceau and Boadway 1994; Palda 2000; Luttmer 2007; Lee and Saez 2012; Gerritsen 2017). ${ }^{18}$ What has not previously been recognized is that the rationing schedule also crucially determines the effect of the minimum wage on government revenue. This is illustrated by the left-hand side of equation (20). On the one hand, the increase in high-skilled employment leads to an increase in public revenue if the high-skilled pay more taxes than the low-skilled (i.e. if $\left.\tau^{H}>\tau^{L}\right)$. This increase in revenue is larger if rationing induces more individuals to become high-skilled (i.e. if $\rho$ is larger). On the other hand, the increase in unemployment leads to a reduction in public revenue if the low-skilled pay more taxes than the unemployed (i.e. if $\tau^{L}>\tau^{U}$ ). The reduction in revenue is larger if rationing leads to more unemployment (i.e. if $\rho$ is smaller). Thus the net effect on revenue crucially depends on the tax wedges $\left(\tau^{H}-\tau^{L}\right)$ and $\left(\tau^{L}-\tau^{U}\right)$, and on the fraction of rationing $\rho$ that is concentrated on individuals who prefer high-skilled employment over unemployment.

Provided that taxes are increasing with income, Proposition 1 shows that an increase in the minimum wage may be desirable only if its effect on high-skilled employment is sufficiently large. Thus the minimum wage is a second-best instrument to alleviate tax distortions on the skill margin. If the government redistributes from the high-skilled to the low-skilled and from the low-skilled to the unemployed, then it does so by setting distortionary taxes on skill formation $\left(\tau^{H}>\tau^{L}\right)$ and low-skilled labour participation $\left(\tau^{L}>\tau^{U}\right)$. By raising high-skilled employment and unemployment, the NIN minimumwage increase alleviates the tax-induced distortion on skill formation and exacerbates the tax-induced distortion on low-skilled participation. That is, it generates a negative fiscal externality by increasing unemployment and a positive fiscal externality by increasing high-skilled employment. Proposition 1 establishes a second-best role for the minimum wage if the revenue gains from reduced distortions in skill formation are large enough to compensate for the revenue losses of increased participation distortions and the utility losses of inefficient rationing.

Notice that the case for or against the minimum wage does not depend on subjective preference for redistribution from the high-skilled to the low-skilled, or on the magnitude of the empirically controversial labour-demand response to the minimum wage. That is, marginal utilities and the demand elasticity are absent from the desirability condition in equation (20). Intuitively, marginal utilities of the highand low-skilled do not matter because we compare an increase in the minimum wage with a distributionally equivalent tax reform. Because both policy reforms redistribute the same amount of resources, the only relevant matter is whether a minimum wage does this more or less efficiently than the tax system. Moreover, the wage elasticity of labour demand is irrelevant because both the relative costs of a higher minimum wage (revenue losses of more unemployment and utility losses of rationing) and the relative benefits of a higher minimum wage (revenue gains of more high-skilled employment) are proportional to the total reduction in low-skilled 
employment. It is not the amount of rationing that matters. Instead, it is the proportion of rationed individuals who become high-skilled workers $(\rho)$ that crucially determines the desirability of a higher minimum wage.

\section{A necessary condition}

Proposition 1 shows that the desirability of an increase in the minimum wage must be driven by its effect on skill formation. However, the desirability condition in equation (20) has two drawbacks. First, even though it does not depend on the marginal utilities of high- and low-skilled workers, it does depend on the change in utility of rationed individuals, which we cannot measure empirically. Second, it also depends on the rationing schedule, particularly on the value of $\rho$, which is similarly hard to measure. Fortunately, both drawbacks can be alleviated by recognizing that the utility losses are weakly positive and thus have a lower bound of zero. An increase in the minimum wage can therefore be more desirable than a distributionally equivalent change in taxes only if the left-hand side of equation (20) is positive. This provides us with a necessary condition for the desirability of an increase in the minimum wage that does not require any knowledge on either the social valuation of utility or the rationing schedule. This is established by the following result.

Corollary 1. A necessary condition for a minimum-wage increase to be more desirable than a distributionally equivalent change in the tax system is that an NIN minimumwage increase raises public revenue $(\mathrm{d} \mathcal{B}>0)$ :

$$
\left(\tau^{H}-\tau^{L}\right) \frac{\rho}{1-\rho}>\left(\tau^{L}-\tau^{U}\right)
$$

Or, equivalently,

$$
\left(\tau^{H}-\tau^{L}\right) \frac{\mathrm{d} H}{\mathrm{~d} U}>\left(\tau^{L}-\tau^{U}\right) .
$$

Proof. Equate the right-hand side of equation (20) to zero and rewrite the expression to obtain equation (21). Substitute for equations (17) and (19) to obtain equation (22).

Thus an NIN increase in the minimum wage can be desirable only if it raises public revenue. There are two special cases in which $\mathrm{d} \mathcal{W} / \lambda=0$, so that equation (21) or (22) is both a necessary and a sufficient condition for an increase in the minimum wage to be desirable. The first special case is obtained if rationing is efficient and there is no preexisting rationing. In that case, rationed individuals do not suffer utility losses because they are indifferent between low-skilled employment and unemployment or high-skilled employment. The second special case is obtained if social preferences are Rawlsian rather than utilitarian, so that we can write $\mathcal{W}=V^{U}$ instead of equation (13). With Rawlsian preferences, the government simply does not care about the utility losses of rationed low-skilled workers, so that $\mathrm{d} \mathcal{W} / \lambda=0$.

Equation (21) once more illustrates the critical importance of the rationing schedule as captured by $\rho$. An increase in the minimum wage, compared to a distributionally equivalent change in taxes, is more likely to raise revenue if rationing leads to more highskilled employment, that is, if $\rho$ is higher. Given that we lack information on the 
rationing schedule, $\rho /(1-\rho)$ could be anywhere between zero and infinity. Fortunately, equation (22) shows that we can rewrite this term as the increase in high-skilled employment relative to the increase in unemployment: $\rho /(1-\rho)=\mathrm{d} H / \mathrm{d} U$. Thus we do not need any knowledge of the rationing schedule if we can obtain a measure of $\mathrm{d} H / \mathrm{d} U$. In other words, the causal effect of unemployment on high-skilled employment-for given net wages - can function as a sufficient statistic for the rationing schedule (cf. Chetty 2009).

We can use Corollary 1 to determine whether an increase in the minimum wage is possibly desirable (if equation (22) holds) or certainly undesirable (if equation (22) is violated) by using empirical estimates of the relevant tax wedges on unemployment $\left(\tau^{L}-\tau^{U}\right)$ and skill formation $\left(\tau^{H}-\tau^{L}\right)$, and the effect of low-skilled unemployment on skill formation $\mathrm{d} H / \mathrm{d} U$. As mentioned before, there is a sizeable literature that estimates the effects of low-skilled unemployment on school enrollment rates (e.g. Clark 2011). These, together with the tax wedges on unemployment and schooling, could be used to calibrate equation (22). ${ }^{19}$ Unfortunately, the estimates on schooling responses all rely on business-cycle variation in unemployment rates, while the rationing associated with the minimum wage is more structural in nature. Moreover, the high-skilled employment response is probably not fully captured by changes in formal schooling but also includes job-to-job transitions to higher-skilled occupations. Corollary 1 therefore highlights the need for more empirical research into the effects of structural low-skilled unemployment on high-skilled employment.

\section{A binding minimum wage as part of the overall optimum}

Proposition 1 and Corollary 1 can be applied to evaluate the desirability of a minimumwage increase for any given allocation. An allocation that is of particular interest is the tax optimum in absence of a minimum wage. If an NIN minimum-wage increase is desirable in the tax optimum, then a minimum wage must be part of the overall optimum. The tax optimum is defined by the set of taxes $\left\{\tau^{U}, \tau^{L}, \tau^{H}\right\}$ that maximizes the social welfare function in equation (13) subject to the government budget constraint in equation (14). Deriving the tax optimum in the absence of a binding minimum wage, and evaluating the desirability condition of the minimum wage at this allocation, yields the following result.

Proposition 2. In the absence of a binding minimum wage, the optimal tax system features taxes that are increasing with income: $\tau^{H}>\tau^{L}>\tau^{U}$. As a result, a binding minimum wage is part of the overall optimum if rationing is sufficiently efficient and $\rho$ sufficiently high at the tax optimum.

Proof. We prove the first part of the proposition in the Appendix. The second part follows immediately from imposing $\tau^{H}>\tau^{L}>\tau^{U}$ on the desirability condition in Proposition 1.

The first part of Proposition 2 is intuitively straightforward. The government optimally redistributes from the employed to the unemployed because the marginal utility of consumption of the employed is smaller than that of the unemployed. It therefore sets $\tau^{L}>\tau^{U}$. Similarly, the government optimally redistributes from the high-skilled to the low-skilled because the marginal utility of consumption of the high-skilled is smaller than that of the low-skilled. It therefore sets $\tau^{H}>\tau^{L}$. Given that optimal taxes are increasing 
with income, increases in high-skilled employment lead to revenue gains, and increases in unemployment lead to revenue losses. From Proposition 1, it then follows that a binding minimum wage is potentially part of the overall optimum. Starting from the overall tax optimum, it is optimal to introduce a minimum wage if $\rho$ is sufficiently high - so that an NIN minimum-wage increase leads to revenue gains - and rationing is sufficiently efficient— so that the utility losses are limited.

\section{Relation to the literature}

The two studies that are most closely related to ours are Marceau and Boadway (1994) and Lee and Saez (2012). Marceau and Boadway (1994) consider a model with exogenous skills. They find that a minimum wage can be desirable only if the low-skilled employed pay less taxes than the unemployed, so that an increase in unemployment leads to revenue gains. Lee and Saez (2012) draw the same conclusion in their Proposition 3, which also considers exogenously given skills. We capture these results as special cases. To see this, consider $\rho=0$, which would imply that the skill distribution is unaffected by rationing. In that case, Proposition 1 shows that a minimum wage can be desirable only if the lowskilled employed pay less taxes than the unemployed $\left(\tau^{L}<\tau^{U}\right)$-as in Marceau and Boadway (1994) and Proposition 3 in Lee and Saez (2012). This could be the case with sufficiently generous in-work benefits. Intuitively, if tax policy yields an upward distortion of low-skilled participation, then a minimum wage alleviates this distortion by rationing individuals out of the low-skilled labour market. ${ }^{20} \mathrm{We}$ generalize these findings by allowing for endogenous skill formation. Contrary to earlier studies, we show in Proposition 1 that a minimum wage can be desirable even if participation is taxed. The reason for this is that a minimum-wage increase raises both unemployment and highskilled employment.

Lee and Saez (2012) do allow for endogenous skill formation in their Proposition 2, while assuming that rationing is efficient and income taxes are optimally set. They consider a different policy reform. Instead of a minimum-wage increase, they study an increase in the low-skilled transfer, while keeping low-skilled wages constant with a minimum wage. A binding minimum wage must be part of the policy optimum if this reform is desirable in the tax optimum without a minimum wage. They find that this is the case if the social welfare weight of the low-skilled exceeds 1 , or, in our notation, if $b^{L} \equiv v^{\prime}\left(c^{L}\right) / \lambda>1$. It can be shown that the desirability condition in Proposition 1 can be reduced to $b^{L}>1$ only if rationing is indeed efficient and taxes are set optimally (Gerritsen and Jacobs 2016). Contrary to Proposition 2 of Lee and Saez (2012), our desirability condition is valid for any efficient or inefficient rationing schedule, and can be evaluated at any allocation inside or outside the tax optimum. ${ }^{21}$ Furthermore, our necessary condition in Corollary 1 does not depend on social welfare weights, but consists only of variables with empirical counterparts.

\section{Robustness}

In deriving our results, we made a number of assumptions that warrant further discussion.

Sequencing of rationing and participation decisions. We assumed that individuals make their labour-supply decisions after they find out whether they are rationed out of the lowskilled labour market. Consequently, they can still move into high-skilled employment if 
they are unable to find a low-skilled job. Alternatively, we could assume that individuals make their participation decisions before knowing whether they will be rationed out of the low-skilled labour market. In that case, individuals take into account that there is a positive probability that they lose their low-skilled job. In Online Appendix B, we show that Proposition 1 and Corollary 1 carry over in modified form to this different sequencing of labour-supply decisions and rationing realizations. Our results remain qualitatively unaffected if we adopt this alternative sequencing of rationing realizations and labour-supply decisions. In particular, compared to a change in income taxes, a minimum-wage increase causes additional rationing. This raises the probability of lowskilled unemployment and thereby induces some individuals to switch to high-skilled employment. Welfare effects consist of utility losses from rationing and public revenue gains and losses from increased high-skilled employment and unemployment. As a result, a minimum-wage increase is desirable if and only if the revenue gains from additional high-skilled employment are large enough to offset any revenue and utility losses from higher unemployment.

Multidimensional heterogeneity. We restricted our model by assuming that all differences between individuals can be captured by ability $\theta$. A more general setup allows individuals to differ in low-skilled ability $\theta^{L}$ and high-skilled ability $\theta^{H}$, both drawn from some joint distribution $G\left(\theta^{L}, \theta^{H}\right)$. Disutility of low-skilled work would equal $1 / \theta^{L}$, and disutility of high-skilled work would equal $1 / \theta^{H}$. ${ }^{22}$ Labour-supply decisions then depend on both $\theta^{L}$ and $\theta^{H}$. This more general setup allows for a high-skilled participation margin; that is, it allows for individuals that are indifferent between unemployment and highskilled employment, and prefer both options over low-skilled employment. This is ruled out in the case of one-dimensional heterogeneity. In Online Appendix C, we extend our model to allow for two-dimensional heterogeneity. We demonstrate that Proposition 1 and Corollary 1 perfectly carry over to this more general setting. ${ }^{23}$ As we know from Diamond (1980), Saez (2002) and Christiansen (2015), the optimal low-skilled tax might in that case be either greater or smaller than the unemployment tax. Intuitively, the government might want to redistribute from the unemployed to the low-skilled employed in order to alleviate distortions on the high-skilled participation margin. If $\tau^{H}>\tau^{U}>\tau^{L}$ in the tax optimum, then a minimum wage would always generate more revenue than a distributionally equivalent tax change. As low-skilled participation is distorted upwards and skill formation is distorted downwards, rationing alleviates both distortions by raising unemployment and high-skilled employment. As a result, the necessary condition of Corollary 1 would in that case be fulfilled. Proposition 1 still requires rationing to be sufficiently efficient for a minimum-wage increase to be more desirable than a distributionally equivalent change in taxation.

Number of skill types. We could extend the model by allowing for more than two skill types in production as well as for multiple other factors of production. In that case, only the lowest skill type would be subject to a binding minimum wage. Our results would remain unaffected, provided that the government is able to tax every factor of production separately, so that the redistributive effects of a minimum wage can be perfectly mimicked by a distributionally equivalent tax reform. The same argument is made by Lee and Saez (2012).

Intensive margin. We could allow individuals to decide on both their skill type and the number of hours that they work. This generates income inequality among individuals 
with the same skill type if their ability also affects disutility of working hours. Given that the government could enforce a binding minimum wage, informational consistency requires that the government sets skill-specific income taxes. We show in Gerritsen and Jacobs (2014) that this would leave our results on the desirability of an NIN minimumwage increase unaffected. ${ }^{24}$

\section{CONCLUSION}

Is a minimum wage an appropriate instrument for redistribution? To answer this question, this paper compares the minimum wage with income taxation in an occupational-choice model with competitive labour markets. Compared to a distributionally equivalent change in taxes, a higher minimum wage raises low-skilled wage costs, which leads to low-skilled labour rationing. The distribution of labour rationing critically determines the desirability of a minimum wage. Depending on which individuals are rationed out of the labour market, some of them become unemployed while others decide to upgrade their skills in order to avoid unemployment and find high-skilled employment instead. If taxes are increasing with income, then rationed individuals who become unemployed pay less taxes, while those who become high-skilled pay more taxes. Moreover, if rationing is inefficient, then it causes utility losses because rationed individuals become involuntarily unemployed or involuntarily high-skilled employed. A minimum-wage increase is more desirable than a distributionally equivalent tax change if and only if the revenue gains from increased highskilled employment outweigh both the revenue losses from increased unemployment and the utility losses from inefficient rationing.

A necessary condition for the desirability of a minimum wage is that the revenue gains from increased high-skilled employment outweigh the revenue losses from increased unemployment. We express this condition in terms of three sufficient statistics: the tax wedge on participation, the tax wedge on skill formation, and the increase in high-skilled employment for a given increase in unemployment. The logical next step is to bring the necessary condition for the desirability of the minimum wage to the data. While there is empirical evidence that unemployment raises enrolment in education, this evidence is almost exclusively based on the effects of variations in business-cycle unemployment on high-school enrolment rates (e.g. Clark 2011). An important avenue for further research is to obtain plausibly causal evidence on the effects of structural unemployment on educational attainment and occupational choice. Along with data on the tax wedges on unemployment and skill formation, this would allow us to calibrate the desirability condition and determine whether a minimum wage increase is more or less desirable than income redistribution via income taxes.

Other promising directions for future research on the desirability of minimum wages are the following. First, our general rationing schedule may be fruitfully applied to analyse the desirability of minimum wages in settings with non-competitive labour markets. Recent empirical evidence on minimum wages suggests that monopsony power may be a relevant feature of low-skilled labour markets (Manning 2016). Second, to rationalize the use of a minimum wage for income redistribution, further research may resort to nonwelfarist notions of justice or non-standard individual preferences. That is, a non-welfarist may argue that all working individuals should be able to earn a sufficiently high 'living wage' in the private sector without relying on government transfers. Alternatively, individuals might care about the source of their income, and derive more satisfaction from wage payments than from government transfers (for evidence, see Akay et al. 2012). Third, further research might find a useful role for a minimum wage that applies to only a

(C) 2019 The Authors. Economica published by John Wiley \& Sons Ltd on behalf of London School of Economics and 
subset of the working population, such as industry- or age-specific minimum wages (see also Kabátek 2015; Kreiner et al. 2019). Indeed, our study suggests that minimum wages may best be targeted to a subset of workers who have the highest propensity to continue schooling if rationed out of the low-skilled labour market—such as the working youth.

\section{APPENDIX A: PROOFS}

Proof of Lemma 2. By Lemma 1, the NIN minimum-wage increase features $\mathrm{d}\left(w^{i}-\tau^{i}\right)=0$ for $i \in\{H, L, U\}$. Substitute this into the derivatives of equations (1)-(6) to obtain equation (16). Take derivatives of equations (7)-(9) and substitute for equation (16) to find the first equalities in equations (17)-(19). Take the total derivative of equation (12) and substitute for $H F_{L H}=-L F_{L L}$, which follows from homogeneity of degree zero of the marginal products, to find $\mathrm{d} H / H-\mathrm{d} L / L=\varepsilon \mathrm{d} w^{L} / w^{L}$, where $\varepsilon \equiv-F_{L} /\left(L F_{L L}\right)>0$. Substitute for $\mathrm{d} H$ and $\mathrm{d} L$ from the first equalities of equations (17) and (18), and for the definition of $\rho$ from equation (15), to obtain $\int_{\Theta_{1}}^{\Theta_{3}} \mathrm{~d} u_{\theta} \mathrm{d} G(\theta)=\alpha \varepsilon \frac{\mathrm{d}_{w^{L}}}{w^{L}}$, with $\alpha \equiv(1 / L+\rho / H)^{-1}>0$. Use the last result, along with the definition of $\rho$, to find the second equalities in equations (17)-(19). The final inequalities follow from $\alpha, \varepsilon>0$ and $\rho \in[0,1]$.

Proof of Proposition 1. The total effect of the NIN minimum-wage increase on social welfare equals $\mathrm{d} \mathcal{W} / \lambda+\mathrm{d} \mathcal{B}$, and $\mathrm{d} \mathcal{W} / \lambda$ is obtained by taking the total derivative of equation (13):

$$
\frac{\mathrm{d} \mathcal{W}}{\lambda}=-\int_{\Theta_{1}}^{\Theta_{2}}\left(\frac{V_{\theta}^{L}-V^{U}}{\lambda}\right) \mathrm{d} u_{\theta} \mathrm{d} G(\theta)-\int_{\Theta_{2}}^{\Theta_{3}}\left(\frac{V_{\theta}^{L}-V_{\theta}^{H}}{\lambda}\right) \mathrm{d} u_{\theta} \mathrm{d} G(\theta) .
$$

We used equations (4)-(6), which imply that marginal changes in the critical levels of ability do not affect social welfare. Multiply and divide the first term by $\int_{\Theta_{1}}^{\Theta_{2}} \mathrm{~d} u_{\theta} \mathrm{d} G(\theta)$, and the second term by $\int_{\Theta_{2}}^{\Theta_{3}} \mathrm{~d} u_{\theta} \mathrm{d} G(\theta)$, substitute for equations (17) and (19), and use the definitions of $\bar{V}_{12}^{L}, \bar{V}_{23}^{L}$ and $\bar{V}_{23}^{H}$ to obtain

$$
\frac{\mathrm{d} \mathcal{W}}{\lambda}=-\left[(1-\rho)\left(\frac{\bar{V}_{12}^{L}-V^{U}}{\lambda}\right)+\rho\left(\frac{\bar{V}_{23}^{L}-\bar{V}_{23}^{H}}{\lambda}\right)\right] \alpha \varepsilon \frac{\mathrm{d} w^{L}}{w^{L}} .
$$

The effect of the NIN minimum-wage increase on $\mathcal{B}$ is obtained by taking the total derivative of equation (14):

$$
\mathrm{d} \mathcal{B}=\tau^{U} \mathrm{~d} U+\tau^{L} \mathrm{~d} L+\tau^{H} \mathrm{~d} H+L \mathrm{~d} \tau^{L}+H \mathrm{~d} \tau^{H}
$$

Substitute for $\mathrm{d} H, \mathrm{~d} L$ and $\mathrm{d} U$ from equations (17)-(19), and for $\mathrm{d} \tau^{H}=-(L / H) \mathrm{d} \tau^{L}$ from Lemma 1, to obtain

(A4) $\quad \mathrm{d} \mathcal{B}=\left[\rho\left(\tau^{H}-\tau^{L}\right)-(1-\rho)\left(\tau^{L}-\tau^{U}\right)\right] \alpha \varepsilon \frac{\mathrm{d} w^{L}}{w^{L}}$. 
Finally, the NIN increase in the minimum wage raises social welfare if and only if $\mathrm{d} \mathcal{W} / \lambda+\mathrm{d} \mathcal{B}>0$. Substitute for equations (A2) and (A4) to establish the proposition.

Proof of Proposition 2. In the absence of a binding minimum wage, there is no rationing (i.e. $u_{\theta}=0$ for all $\theta$ ) and the low-skilled wage is endogenously determined by equation (12). Without rationing, equations (7) and (9) indicate that unemployment is determined by the critical ability level $\Theta_{1}$, and high-skilled employment is determined by the critical level $\Theta_{3}$. Moreover, from equations (4) and (6) we know that $\Theta_{1}$ depends only on the net incomes of the unemployed and the low-skilled employed, and $\Theta_{3}$ depends only on the net incomes of the low-skilled employed and the high-skilled employed. Accordingly, we can write unemployment as a function $U=\widetilde{U}\left(c^{U}, c^{L}\right)$, which is increasing in $c^{U}=-\tau^{U}$ and decreasing in $c^{L}=w^{L}-\tau^{L}$. Similarly, we can write highskilled employment as a function $H=\widetilde{H}\left(c^{L}, c^{H}\right)$, which is decreasing in $c^{L}$ and increasing in $c^{H} \equiv w^{H}-\tau^{H}$. Low-skilled employment follows residually from $L=1-U-H$.

It is easiest to solve for the tax optimum by using the primal approach. That is, we maximize social welfare subject to the economy's resource constraint with respect to the allocation (i.e. net wages $c^{i}$ ) rather than taxes $\tau^{i}$. Substituting for equations (1)-(3), $\tau^{i}=w^{i}-c^{i}$, and $u_{\theta}=0$ for all $\theta$ into the social welfare function of equation (13) yields

$$
\mathcal{W}=\int_{0}^{\Theta_{1}} v\left(c^{U}\right) \mathrm{d} G(\theta)+\int_{\Theta_{1}}^{\Theta_{3}}\left(v\left(c^{L}\right)-\frac{1}{\theta}\right) \mathrm{d} G(\theta)+\int_{\Theta_{3}}^{\bar{\theta}}\left(v\left(c^{H}\right)-\frac{1+\beta}{\theta}\right) \mathrm{d} G(\theta) .
$$

Notice that equations (4) and (6) imply that marginal changes in $\Theta_{1}$ or $\Theta_{3}$ do not affect social welfare. Substituting for $\tau^{i}=w^{i}-c^{i}$ and $U=\widetilde{U}\left(c^{U}, c^{L}\right), H=\widetilde{H}\left(c^{L}, c^{H}\right)$ and $L=1-U-H$ into the budget constraint of equation (14) yields the economy's resource constraint:

$$
\mathcal{B}=w^{L}-c^{L}-\left(w^{L}-c^{L}+c^{U}\right) \widetilde{U}\left(c^{U}, c^{L}\right)+\left(w^{H}-c^{H}-w^{L}+c^{L}\right) \widetilde{H}\left(c^{L}, c^{H}\right)-R .
$$

Notice that marginal changes in gross wages do not directly affect the budget constraint. To see this, recall from Lemma 1 that $\mathrm{d} w^{H}=-(L / H) \mathrm{d} w^{L}$. Taking the derivative of equation (A6) with respect to gross wages, while leaving net wages constant, thus yields

$$
(1-U-H) \mathrm{d} w^{L}+H \mathrm{~d} w^{H}=L \mathrm{~d} w^{L}+H \mathrm{~d} w^{H}=0 .
$$

As usual, the Lagrangian for the government optimization problem can be written as $\mathcal{L} \equiv \mathcal{W}+\lambda \mathcal{B}$. Substituting for equations (A5) and (A6), and taking derivatives with respect to $c^{H}, c^{L}$ and $c^{U}$, yields the following first-order conditions:

$$
\begin{aligned}
& \frac{1}{\lambda} \frac{\partial \mathcal{L}}{\partial c^{H}}=\left(\frac{v^{\prime}\left(c^{H}\right)}{\lambda}-1\right) H+\left(w^{H}-c^{H}-w^{L}+c^{L}\right) \frac{\partial \widetilde{H}}{\partial c^{H}}=0, \\
& \frac{1}{\lambda} \frac{\partial \mathcal{L}}{\partial c^{L}}=\left(\frac{v^{\prime}\left(c^{L}\right)}{\lambda}-1\right) L-\left(w^{L}-c^{L}+c^{U}\right) \frac{\partial \widetilde{U}}{\partial c^{L}}+\left(w^{H}-c^{H}-w^{L}+c^{L}\right) \frac{\partial \widetilde{H}}{\partial c^{L}}=0, \\
& \frac{1}{\lambda} \frac{\partial \mathcal{L}}{\partial c^{U}}=\left(\frac{v^{\prime}\left(c^{U}\right)}{\lambda}-1\right) U-\left(w^{L}-c^{L}+c^{U}\right) \frac{\partial \widetilde{U}}{\partial c^{U}}=0 .
\end{aligned}
$$


To obtain these first-order conditions, we used the fact that marginal changes in critical ability levels and gross wages do not affect the Lagrangian. These first-order conditions can be rewritten in terms of welfare weights, tax wedges and elasticities. Substituting for social welfare weights $b^{i} \equiv v^{\prime}\left(c^{i}\right) / \lambda$, net income $c^{i} \equiv w^{i}-\tau^{i}$, and elasticities

$$
\begin{aligned}
\varepsilon_{\tau^{H}}^{H} & \equiv \frac{\partial \widetilde{H}}{\partial c^{H}} \frac{c^{H}-c^{L}}{H}>0, \quad \varepsilon_{\tau^{L}}^{H} \equiv-\frac{\partial \widetilde{H}}{\partial c^{L}} \frac{c^{H}-c^{L}}{H}>0 \\
\varepsilon_{\tau^{L}}^{U} & \equiv-\frac{\partial \widetilde{U}}{\partial c^{L}} \frac{c^{L}-c^{U}}{U}>0, \quad \text { and } \quad \varepsilon_{\tau^{U}}^{U} \equiv \frac{\partial \widetilde{U}}{\partial c^{U}} \frac{c^{L}-c^{U}}{U}>0
\end{aligned}
$$

yields

$$
\begin{aligned}
& 1-b^{H}=\left(\frac{\tau^{H}-\tau^{L}}{c^{H}-c^{L}}\right) \varepsilon_{\tau^{H}}^{H}, \\
& 1-b^{L}=\left(\frac{\tau^{L}-\tau^{U}}{c^{L}-c^{U}}\right) \frac{U}{L} \varepsilon_{\tau^{L}}^{U}-\left(\frac{\tau^{H}-\tau^{L}}{c^{H}-c^{L}}\right) \frac{H}{L} \varepsilon_{\tau^{L}}^{H}, \\
& 1-b^{U}=-\left(\frac{\tau^{L}-\tau^{U}}{c^{L}-c^{U}}\right) \varepsilon_{\tau^{U}}^{U} .
\end{aligned}
$$

In the tax optimum, the redistributional gains of each tax instrument—given by the lefthand sides of equations (A10)-(A12) - must equal their marginal dead-weight lossesgiven by the right-hand sides of equations (A10)-(A12).

We can prove by contradiction that equations (A10)-(A12) imply $\tau^{H}>\tau^{L}>\tau^{U}$. First note that any equilibrium with both high- and low-skilled workers must necessarily have $w^{H}-\tau^{H}>w^{L}-\tau^{L}>-\tau^{U}$. Together with strict concavity of $v(\cdot)$, this implies that social welfare weights are strictly decreasing in income: $b^{U}>b^{L}>b^{H}$. Now consider $\tau^{U} \geq \tau^{L}$. Equation (12) then implies that $b^{U} \leq 1$. Moreover, equations (10) and (11) then imply that $b^{L} \geq 1$ if $\tau^{H} \geq \tau^{L}$, and $b^{H} \geq 1$ if $\tau^{H} \leq \tau^{L}$. This contradicts decreasing welfare weights. Thus in the optimum we must have that $\tau^{L}>\tau^{U}$. Now consider $\tau^{L} \geq \tau^{H}$. Equation (10) then implies that $b^{H} \geq 1$. Moreover, equations (11) and (12) then imply that $b^{L} \leq 1$ if $\tau^{L} \geq \tau^{U}$, and $b^{U} \leq 1$ if $\tau^{L} \leq \tau^{U}$. This again contradicts decreasing welfare weights. Thus in the optimum we must have that $\tau^{H}>\tau^{L}$.

\section{ACKNOWLEDGMENTS}

We are grateful to the Editor, Stephen Machin, and two anonymous referees for their insightful and constructive remarks. We also thank Robin Boadway, Johann Brunner, Carlos da Costa, Laurence Jacquet, Etienne Lehmann, Emmanuel Saez, Coen Teulings, Hendrik Vrijburg, Floris Zoutman, and participants at numerous seminars and conferences for helpful comments and discussions.

Financial support from the Netherlands Organization for Scientific Research (NWO Vidi Grant no. 452-07-013) and the Netherlands Institute for Advanced Study (Wim Duisenberg Fellowship 2018-2019) is gratefully acknowledged. 


\section{NOTES}

1. Indeed, the empirical literature on the economic consequences of the minimum wage is too vast to summarize. For a number of recent contributions, see Cengiz et al. (2019) on employment and wages, Harasztosi and Lindner (2019) on employment, revenue, profits and capital stocks, and Bell and Machin (2018) on the stock-market value of firms.

2. For copies of these letters, see Aaron et al. (2014) and Smith et al. (2014).

3. Our conclusions do not in any way depend on this particular reform, but it allows for the most transparent comparison between a minimum wage and the tax and transfer system.

4. In the working paper version of this paper, we provide a first pass at calibrating the necessary condition for the desirability of a minimum wage (Gerritsen and Jacobs 2016). We find that a minimum wage is strictly less desirable than a distributionally equivalent change in taxes for most OECD countries, except possibly the USA. However, to forcefully make this claim, one requires more reliable causal estimates on the effects of structural unemployment on skill formation than the literature currently provides.

5. They do find a potentially useful role for the minimum wage if income taxation is restricted to a linear tax rate. This is because a minimum wage can redistribute income in a way that a linear income tax cannot; see also Gerritsen and Jacobs (2013).

6. Outside the optimum, their condition is informative only about the desirability of raising low-skilled transfers, but not about the desirability of raising the minimum wage.

7. Our baseline model corresponds to the occupational-choice model of Saez (2002) with a low-skilled participation margin and a skill margin, but without a high-skilled participation margin. The model in Online Appendix C corresponds to the general case of Saez (2002) with both high- and low-skilled participation margins and a skill margin.

8. If this condition is violated, then either no individual wants to be high-skilled or no individual wants to be low-skilled. In particular, if $\Theta_{3}>\bar{\theta}$, then every individual prefers to be either low-skilled or unemployed. Moreover, if $\Theta_{3}<\Theta_{1}$, then every individual prefers to be either high-skilled or unemployed. If $\bar{\theta}>\Theta_{3}>\Theta_{1}$, then equations (4)-(6) imply that $\Theta_{3}>\Theta_{2}>\Theta_{1}$.

9. The rationing rate does not necessarily correspond to the standard definition of the unemployment rate, because rationed individuals with ability $\theta \in\left[\Theta_{2}, \Theta_{3}\right]$ decide to become high-skilled rather than unemployed.

10. Efficient rationing implies that only individuals with ability close to $\Theta_{1}$ or $\Theta_{3}$ are unable to find a low-skilled job. These individuals are indifferent between low-skilled employment on the one hand, and involuntary unemployment or high-skilled employment on the other. Uniform rationing implies that the rationing rate is independent from ability, so that $u_{\theta}=u$ for all $\theta \in\left[\Theta_{1}, \Theta_{3}\right]$.

11. Equations (11) and (12) uniquely pin down the ratio of production factors $H^{d} / L^{d}$, but not the scale of production. The equilibrium scale of production is determined by equating labour demand ( $H^{d}$ and $L^{d}$ as given by equations (11) and (12)) and supply ( $H$ and $L$ as determined by equations (7) and (8)).

12. This contrasts with a number of previous studies that are 'informationally inconsistent' (e.g. Guesnerie and Roberts 1987; Allen 1987; Marceau and Boadway 1994; Boadway and Cuff 2001; Blumkin and Danziger 2018; Danziger and Danziger 2015). These studies assume that information on individual wages can be used to enforce a minimum wage, but not to condition taxes and transfers on wages, since this would allow the government to reach first-best. In our case, as in Lee and Saez (2012), first-best cannot be reached even with wage-specific taxes because individuals are heterogeneous with respect to disutility of work instead of wages.

13. For empirical evidence on the distributional effects of the US minimum wage, see, for example Teulings (2003) and Autor et al. (2016). For the distributional effects of the US tax system, see Piketty and Saez (2007).

14. As we demonstrate in Gerritsen and Jacobs (2013), the comparative statics and welfare effects of changes in the minimum wage in isolation from taxes, or taxes in isolation from the minimum wage, are straightforward, but mathematically tedious and notationally elaborate.

15. As will become apparent below, the reform may still reduce utility of the individuals who are rationed out of the low-skilled labour market. Thus while the utility losses from inefficient rationing are relevant for our analysis, the valuation of redistribution from rich to poor is not.

16. Our approach is comparable to Christiansen $(1981,1984)$ and Kaplow $(2008)$, among others. They study combined reforms that raise a consumption tax (or public good provision, the tax on capital income, etc.) while offsetting all distributional implications by appropriate changes in the non-linear income tax. Like us, they obtain simple desirability conditions that do not depend on social preferences for income redistribution.

17. Moreover, there is a large empirical literature that finds a significant direct effect of minimum wages on education. This literature is somewhat mixed. For example, Arulampalam et al. (2004) and Dustmann and Schönberg (2009) find positive effects of the minimum wage on education, whereas Neumark and Wascher (1995) and Montmarquette et al. (2007) find negative effects. However, studies that find a negative effect of the minimum wage on education typically control for the unemployment rate. These findings may thus be in line with our theoretical model, which predicts that a positive relationship between the minimum wage and skill formation would run through higher unemployment rates. 
18. The same has been argued for inefficient rationing of specific commodities, such as rental houses (Glaeser and Luttmer 2003), gasoline (Frech and Lee 1987) or residential gas (Davis and Kilian 2011).

19. See our working paper version for a first pass on this (Gerritsen and Jacobs 2016).

20. See also Hummel and Jacobs (2018), who demonstrate that labour unions can be desirable for income redistribution to alleviate the distortions of excessive labour participation caused by participation subsidies.

21. Outside the tax optimum, Lee and Saez (2012) show that their condition $\left(b^{L}>1\right)$ determines the desirability of raising transfers to the low-skilled. However, the condition is not informative about the desirability of raising the minimum wage.

22. The model in the main text is a special case of this more general setup, with $\theta^{H}=\theta^{L} /(1+\beta)$.

23. We also show that the first part of Proposition 2 need not hold in a model with multidimensional heterogeneity.

24. The analysis in Gerritsen and Jacobs (2014) differs in two ways from earlier intensive-margin frameworks by Allen (1987) and Guesnerie and Roberts (1987). First, in their frameworks, the government is restricted by an incentive constraint that the high-skilled should not prefer to 'mimic' the income of the low-skilled by working less hours. This constraint is not relevant in our analysis as the government is assumed to condition its income taxes on skill type. This is required by informational consistency because the government needs to observe skill types in order to enforce the minimum wage. Unlike in Allen (1987) and Guesnerie and Roberts (1987), skill-specific taxes do not lead to a trivial first-best outcome, because individuals differ not only in their skill type, but also in their disutility of work. Second, unlike the earlier studies, we allow for a skill decision. As in the current paper, this skill decision is generating a potential second-best role for the minimum wage.

\section{REFERENCES}

AAron, H. et al. (2014). Over 600 economists sign letter in support of \$10.10 minimum wage. Economics Policy Institute, 14 January; available online at www.epi.org/minimum-wage-statement (accessed 3 August 2019).

Acemoglu, D. (2001). Good jobs versus bad jobs. Journal of Labor Economics, 19(1), 1-21.

Akay, A., Bargain, O., Dolls, M., Neumann, D., Peichl, A. and Siegloch, S. (2012). Happy taxpayers? Income taxation and well-being. IZA Discussion Paper no. 6999. Bonn: IZA.

Allen, S. P. (1987). Taxes, redistribution, and the minimum wage: a theoretical analysis. Quarterly Journal of Economics, 102(3), 477-89.

Arulampalam, W., Booth, A. L. and Bryan, M. L. (2004). Training and the new minimum wage. Economic Journal, 114(494), C87-C94.

Autor, D. H., Manning, A. and Smith, C. L. (2016). The contribution of the minimum wage to US wage inequality over three decades: a reassessment. American Economic Journal: Applied Economics, 8(1), 58-99.

Bell, B. and Machin, S. (2018). Minimum wages and firm value. Journal of Labor Economics, 36(1), 159-95.

Blumkin, T. and DANZiger, L. (2018). Deserving poor and the desirability of a minimum wage. IZA Journal of Labor Economics, 7(6), 1-17.

BoAdway, R. and CufF, K. (2001). A minimum wage can be welfare-improving and employment-enhancing. European Economic Review, 45(3), 553-76.

Cahuc, P. and Laroque, G. (2013). Optimal taxation and monopsonistic labor market: does monopsony justify the minimum wage? Journal of Public Economic Theory, 16(2), 259-73.

- and Michel, P. (1996). Minimum wage unemployment and growth. European Economic Review, 40, 1463-82.

Card, D. and Krueger, A. B. (1995). Myth and Measurement: The New Economics of the Minimum Wage. Princeton, NJ: Princeton University Press.

- and LEMIEUX, T. (2001). Dropout and enrollment trends in the postwar period: what went wrong in the 1970s? In J. Gruber (ed.), Risky Behavior Among Youths: An Economic Analysis. Chicago, IL: University of Chicago Press, pp. 439-82.

Cengiz, D., Dube, A., Lindner, A. and Zipperer, B. (2019). The effect of minimum wages on low-wage jobs: evidence from the United States using a bunching estimator. Quarterly Journal of Economics, 134(3), 14051454.

ChetTy, R. (2009). Sufficient statistics for welfare analysis: a bridge between structural and reduced-form methods. Annual Review of Economics, 1(1), 451-87.

Christiansen, V. (1981). Evaluation of public projects under optimal taxation. Review of Economic Studies, 48 (3), 447-57.

- (1984). Which commodity taxes should supplement the income tax? Journal of Public Economics, 24(2), $195-220$.

(2015). Optimal participation taxes. Economica, 82(328), 595-612. 
Clark, D. (2011). Do recessions keep students in school? The impact of youth unemployment on enrolment in post-compulsory education in England. Economica, 78(311), 523-45.

DAnZiger, E. and DAnZiger, L. (2015). A Pareto-improving minimum wage. Economica, 82(326), $236-52$.

DAVIS, L. W. and KILIAN, L. (2011). The allocative cost of price ceilings in the U.S. residential market for natural gas. Journal of Political Economy, 119(2), 212-41.

Diamond, P. (1980). Income taxation with fixed hours of work. Journal of Public Economics, 13(1), 101-10.

Dustmann, C. and Schönberg, U. (2009). Training and union wages. Review of Economics and Statistics, 91 (2), 363-76.

Foged, M. and Peri, G. (2015). Immigrants' effect on native workers: new analysis on longitudinal data. American Economic Journal: Applied Economics, 2(8), 1-34.

FreCH, H. E. and LEE, W. C. (1987). The welfare cost of rationing-by-queuing across markets: theory and estimates from the U.S. gasoline crises. Quarterly Journal of Economics, 102(1), 97-108.

Gerritsen, A. (2017). Equity and efficiency in rationed labor markets. Journal of Public Economics, 153, 56-68.

- and JACOBS, B. (2013). Minimum wages and taxation in competitive labor markets with endogenous skill formation. Mimeo. Rotterdam: Erasmus University Rotterdam.

_- and (2014). Is a minimum wage an appropriate instrument for redistribution? CESifo Working Paper no. 4588. Munich: CESifo.

_ - and (2016). Is a minimum wage an appropriate instrument for redistribution? Tinbergen Institute Discussion Paper no. TI 2016-100-IV. Amsterdam/Rotterdam: Tinbergen Institute.

Glaeser, E. L. and LutTMer, E. F. (2003). The misallocation of housing under rent control. American Economic Review, 93(4), 1027-46.

Guesnerie, R. and Roberts, K. (1987). Minimum wage legislation as a second best policy. European Economic Review, 31(1-2), 490-8.

Harasztosi, P. and Lindner, A. (2019). Who pays for the minimum wage? American Economic Review, 109(8), 2693-2727.

Hummel, A. J. and Jacobs, B. (2018). Optimal income taxation in unionized labor markets. CESifo Working Paper No. 6599. Munich: CESifo.

HungerbüHler, M. and Lehmann, E. (2009). On the optimality of a minimum wage: new insights from optimal tax theory. Journal of Public Economics, 93(3), 464-81.

KAвÁTEK, J. (2015). Happy birthday, you're fired! The effects of age-dependent minimum wage on youth employment flows in the Netherlands. IZA Discussion Paper no. 9528. Bonn: IZA.

KANE, T. J. (1994). College entry by blacks since 1970: the role of college costs, family background, and the returns to education. Journal of Political Economy, 102(5), 878-911.

KAPLOW, L. (2008). The Theory of Taxation and Public Economics. Princeton, NJ: Princeton University Press.

Kreiner, C. T., Reck, D. and Skov, P. E. (2019). Do lower minimum wages for young workers raise their employment? Evidence from a Danish discontinuity. Review of Economics and Statistics, forthcoming.

LavecchiA, A. M. (2019). Minimum wage policy with optimal taxes and unemployment. Mimeo. Hamilton, ON: McMaster University.

LEE, D. and SAEZ, E. (2008). Optimal minimum wage policy in competitive labor markets. NBER Working Paper no. 14320. Cambridge, MA: NBER.

- - and (2012). Optimal minimum wage policy in competitive labor markets. Journal of Public Economics, 96(9-10), 739-49.

LotT, J. R. (1990). Nontransferable rents and an unrecognized social cost of minimum wage laws. Journal of Labor Research, 11(4), 453-60.

LutTMER, E. F. P. (2007). Does the minimum wage cause inefficient rationing? BE Journal of Economic Analysis \& Policy, 7(1).

Manning, A. (2016). The elusive employment effect of the minimum wage. CEP Discussion Paper no. 1428. London: CEP.

Marceau, N. and Boadway, R. (1994). Minimum wage legislation and unemployment insurance as instruments for redistribution. Scandinavian Journal of Economics, 96(1), 67-81.

MirRleES, J. A. (1971). An exploration in the theory of optimum income taxation. Review of Economic Studies, 38(2), 175-208.

Montmarquette, C., Viennot-Briot, N. and Dagenais, M. (2007). Dropout, school performance, and working while in school. Review of Economics and Statistics, 89(4), 752-60.

Neumark, D. and WAscher, W. (1995). Minimum-wage effects on school and work transitions of teenagers. American Economic Review, 85(2), 244-9.

- and (2006). Minimum wages and employment: a review of evidence from the new minimum wage research NBER Working Paper no. 12663. Cambridge, MA: NBER. 
Palda, F. (2000). Some deadweight losses from the minimum wage: the cases of full and partial compliance. Labour Economics, 7(6), 751-83.

Petrongolo, B. and San Segundo, M. J. (2002). Staying-on at school at 16: the impact of labor market conditions in Spain. Economics of Education Review, 21(4), 353-65.

PIKetTy, T. and SAEZ, E. (2007). How progressive is the U.S. federal tax system? A historical and international perspective. Journal of Economic Perspectives, 21(1), 3-24.

SAEZ, E. (2002). Optimal income transfer programs: intensive versus extensive labor supply responses. Quarterly Journal of Economics, 117(3), 1039-73.

SchmitT, J. (2013). Why does the minimum wage have no discernible effect on employment? Washington, DC: Center for Economic and Policy Research.

SMith, V. et al. (2014). A statement to federal policy makers; available online at http://nebula.wsimg.com/ 0ac0b639d50f7fea43d0378b1ee19215?AccessKeyId= D2418B43C2D698C15401 (accessed 4 August 2019).

STERn, N. (1982). Optimum taxation with errors in administration. Journal of Public Economics, 17(2), 181211.

Stiglitz, J. E. (1982). Self-selection and Pareto efficient taxation. Journal of Public Economics, 17(2), $213-40$.

Teulings, C. N. (2003). The contribution of minimum wages to increasing wage inequality. Economic Journal, 113(490), 801-33.

White House (2013). Remarks by the President on economic mobility, 4 December; available online at https:// www.whitehouse.gov/the-press-office/2013/12/04/remarks-president-economic-mobility (accessed 4 August 2019).

\section{SUPPORTING INFORMATION}

Additional Supporting Information may be found in the online version of this article:

Online Appendix B Labor Supply Decisions Before Rationing is Realized

Online Appendix C Multidimensional Heterogeneity 